\title{
A violência e as experiências coletivas de conflito
}

Violence and Collective Conflict Experiences

La violence et les expériences collectives de conflit

\section{Carlos A. Gadea}

\section{(2) OpenEdition}

\section{Journals}

Edição electrónica

URL: http://journals.openedition.org/rccs/3980

DOI: $10.4000 /$ rccs.3980

ISSN: 2182-7435

\section{Editora}

Centro de Estudos Sociais da Universidade de Coimbra

Edição impressa

Data de publição: 1 Março 2011

Paginação: 75-98

ISSN: 0254-1106

Refêrencia eletrónica

Carlos A. Gadea, "A violência e as experiências coletivas de conflito », Revista Crítica de Ciências Sociais [Online], 92 | 2011, colocado online no dia 01 novembro 2012, criado a 19 abril 2019. URL : http://journals.openedition.org/rccs/3980 ; DOI : 10.4000/rccs.3980 


\section{CARLOS A. GADEA}

\section{A violência e as experiências coletivas de conflito*}

As mobilizações coletivas emergentes, os distúrbios urbanos e as concentrações espontâneas parecem indicar que o cenário do conflito social e o sentido da violência que as acompanham adquirem dimensões diferentes na atualidade. Neste contexto, o presente trabalho procura analisar os eventuais nexos existentes entre a violência e as aqui denominadas experiências coletivas de conflito. Valendo-se das discussões sobre violência, conflito, ações coletivas e "definição de uma situação", a proposta é pensar até que ponto a violência parece constituir-se em um ingrediente muito importante na construção do sentido social das ações coletivas contemporâneas, bem como no estabelecimento de um cenário de conflituosidade social preciso e localizável.

Palavras-chave: experiências de conflito, conflitos urbanos, conflitos sociais, conflitos colectivos de trabalho, violência, ação coletiva, movimentos sociais.

No presente trabalho, procura-se analisar os eventuais nexos existentes entre a violência e as aqui denominadas experiências coletivas de conflito. Para isso, alguns debates lhe devem preceder, como, por exemplo, aquele que explora a necessidade de realizar uma substituição, não meramente semântica, do conceito de movimento social por uma nomenclatura considerada menos rígida e que aspira a compreender as dinâmicas de mobilização e protestos atuais: as experiências coletivas de conflito.

Apesar de a eventual relação entre violência e movimento social ter sido objeto de análise recorrente nas ciências humanas (Sorel, 1993:1 Touraine, 1989; Tilly, 1995; Wieviorka, 2006), foi percebida, na maioria das ocasiões, como uma relação um tanto irrelevante, no sentido de que não aportaria traços significativos para a descrição das transformações políticas e culturais das últimas décadas. Não obstante, e de maneira perceptivelmente crescente, faz-se imprescindível a análise desta dupla conceitual, à medida que as mobilizações emergentes, os distúrbios urbanos coletivos e as concentrações espontâneas

\footnotetext{
* Agradeço ao Sérgio Costa (Freie Universität Berlin) os comentários iniciais à primeira versão desse texto.

${ }^{1}$ Faz-se referência a Reflexões sobre violência numa primeira publicação de 1906.
} 
não parecem ser indicadores de um simples processo de gestação de movimentos sociais, mas sim de "movimentos em si mesmos" ou, melhor dito, de experiências coletivas de conflito. O que aqui se procurará observar e analisar se refere a esta transformação no cenário do "conflito", como também na própria abordagem da forma como é representada a violência na atualidade. Isto se vincula com algumas iniciais constatações significativas: primeiramente, a uma limitada ampliação e consolidação do desafio político e cultural realizado pelos novos movimentos sociais (Evers, 1984; Riechmann e Buey, 1994) em torno, fundamentalmente, da superação do "marco institucional" de ação; e, por outro lado, a uma reduzida capacidade das mudanças realizadas na "estrutura de oportunidades políticas" (Tarrow, 1997) dos últimos tempos para criar incentivos à participação e à expressão política e social em geral.

Muitos lúcidos intelectuais manifestariam o seu descontentamento frente a esta dupla constatação, principalmente quando entendem que, de fato, o "marco institucional" tem-se dilatado significativamente nos últimos vinte anos. Não obstante, o caráter frágil (político e simbólico) das práticas sociais que empiricamente amparariam o dito descontentamento deve ser levado a sério ao tratar o tema aqui abordado. Sendo assim, sem o horizonte da institucionalidade, tão importante nas análises das ações coletivas mais clássicas, ${ }^{2}$ e sem a ampliação efetiva das oportunidades de expressão política e cultural, emergem novos problemas e desafios, nos quais a "ação coletiva contenciosa" (ibidem: 19) parece traduzir-se em experiências coletivas de conflito sob a linguagem da violência. Por isso, é a violência uma velha resposta para um velho desafio? É, tão-somente, uma reação espontânea a diversos mecanismos institucionais, além de pouco expressiva política e culturalmente? Até que ponto a violência é um dado da realidade em absoluto abstrato e faz referência à "definição de uma situação" de conflituosidade? Para poder abordar estas interrogações, refletir-se-á inicialmente sobre três eixos conceituais: a "definição de uma situação", a representação da violência associada a experiências coletivas de conflito e o sentido e significado que elas assumem enquanto tais.

O primeiro eixo conceitual se nutrirá das clássicas contribuições de William I. Thomas (2005), no sentido de contribuir para uma reflexão que coloque as representações sobre a violência como o resultado de uma "definição de uma situação" social específica, estruturadora de experiências coletivas de conflito. Nesse sentido, pode-se perceber que se prevê certo pragmatismo filosófico na base dessa reflexão, algo a ser considerado de grande importância, pois o argumento central aqui é considerar essas experiências como inerentes ao estabelecimento de cenários de conflito e de definições

\footnotetext{
${ }^{2}$ Ver a interessante crítica realizada por Riechmann e Buey (1994: 47-102).
} 
de situações de conflituosidade claros e precisos. O segundo eixo de análises vem argumentar acerca da necessidade de reavaliar se, no contexto atual, não seria inevitável pensar-se em substituir, para algumas situações empíricas concretas, o conceito movimento social pelo que aqui se define como experiências coletivas de conflito. O caráter espontâneo e até de escassa ou nula articulação mobilizatória, somando-se à utilização da violência como mecanismo de expressão, pareceria sugerir que não nos enfrentamos, de forma evidente, a movimentos sociais e sim a ações coletivas que precisam ser ressemantizadas à luz das mudanças políticas e socioculturais contemporâneas. Assim, torna-se importante pensar como compreender ações coletivas que sob a linguagem da violência adquirem visibilidade e, fundamentalmente, conseguem estabelecer um cenário de conflito preciso e estável. Tudo parece indicar que há um evidente deslocamento no objeto a ser analisado: não é mais compreendendo o movimento social que saberemos frente a que definições de situações de conflituosidade nos deparamos, mas sim conhecendo mais sobre a forma do estabelecimento de cenários de conflituosidade é que se poderá compreender o sentido de uma experiência coletiva de conflito.

$\mathrm{O}$ argumento central é evidenciar como a violência não deve ser negligenciada na hora de analisar o sentido e o significado das ações coletivas contemporâneas, já que é a partir da sua expressividade que se percebe o estabelecimento de uma "situação de conflito" que constituirá eventuais experiências coletivas de conflito. As contribuições das análises de autores como Sidney Tarrow (1997), Alain Touraine (1997; 2006a; 2006b) e Michel Wieviorka (2006) serão centrais no desenvolvimento dos argumentos aqui apresentados. O objetivo deste texto é manifestar a importância por ampliar uma definição de ação coletiva que contemple o seu conteúdo contingente, imprevisível e desarticulado, fatores que conduzem a ensaiar definir um conceito mais abrangente. Para ilustrar essa idéia, considerar-se-á um breve exemplo sobre as manifestações de protesto na cidade de Montevidéu após a visita à cidade do outrora presidente dos Estados Unidos, George W. Bush, manifestações em que a violência pareceu tomar centralidade na forma e no próprio conteúdo dessas manifestações.

\section{Questões de discussão}

\section{A situação}

William I. Thomas (1863-1947), um dos principais representantes da Escola de Chicago, afirmava que a partir da "definição de uma situação" dada por um determinado indivíduo ou grupo social se verá condicionada a realidade vivenciada por esse indivíduo ou grupo. Isto quer dizer que, 
se os indivíduos ou grupos sociais definem uma situação como real, essa situação é real nas suas conseqüências. O sentido subjetivo de um grupo e o sentido que um grupo tem para seus membros é, desta maneira, não só entendível nos termos de um sentimento de integração ou comunidade de interesses, mas também nos termos de um sistema comum de tipificações e significados (Schütz, 1962). Sem dúvida, isto representa considerar um processo de evolução dinâmico dos diferentes repertórios de significados subjetivos, na medida em que sempre os indivíduos fazem parte de diversos grupos sociais. Tal qual Simmel (1977) tinha assinalado, cada indivíduo está situado na interseção de vários círculos sociais, que serão tanto mais numerosos quanto mais diferenciada for a personalidade do indivíduo. Isto se deve, fundamentalmente, a que aquilo que outorga singularidade à personalidade é precisamente o que não pode ser compartilhado com os outros.

A idéia de "definição de uma situação" proposta por Thomas (2005) pressupõe que previamente a todo o comportamento autodeterminado existe um "estado de deliberação". Afirma que "no sólo los actos concretos dependen de la definición de la situación, sino que gradualmente toda política de vida o la personalidad del individuo mismo provienen de una serie de definiciones de este estilo" (ibidem: 28). Quer dizer que, nesse aparente caráter reflexivo próprio do "estado de deliberação", o indivíduo tem consciência de si mesmo e também da sua pertença a uma comunidade (Mead, 1982). Thomas, assim mesmo, adverte que sempre se apresenta uma rivalidade entre as definições espontâneas da situação feitas por um indivíduo e as definições que a sociedade lhe tem proporcionado. Assim, resulta evidente o caráter ambivalente deste "estado de deliberação", na medida em que a "sociedade organizada", na sua dinâmica reguladora, faz-se presente através de outras "definições da situação" previamente existentes ao processo de interiorização pelos indivíduos dos dispositivos normativos de ação. Um exemplo pode estar nas crianças, que nascem dentro de um grupo de pessoas para as quais todos os tipos gerais de situação que possam surgir já foram definidos, tendo-se desenvolvido as correspondentes leis de conduta. Assim, para além de a criança aparecer "contida" em "situações" já definidas, aparentemente e de forma fundamental ela não tem a possibilidade de realizar as suas próprias definições nem de continuar os seus desejos sem interferência (ibidem). Pode-se questionar, desta forma, se os seus desejos não seriam também condicionados a priori pelo "universo do discurso", mas esse aspecto não está em questão aqui. O relevante é considerar que, através das suas análises, é possível compreender a existência de uma diversidade de "agentes definidores" e que, no seu entrecruzamento, o próprio indivíduo 
terá uma experiência coletiva particular e uma "definição de uma situação" que o incluirá numa comunidade também particular.

O caráter ambivalente desta idéia proposta por Thomas teria um interessante desdobramento nas análises da institucionalização e do controle social elaboradas por Berger e Luckmann (2001). Mas percebe-se a originalidade de Thomas quando, justamente, procura descobrir o local desse controle social, afirmando que é a comunidade quem regula o comportamento dos seus membros em grande medida falando sobre eles (Thomas, 2005: 30). Por isso, o elemento funcional desta ação é decisivo, no sentido de que é uma maneira de definir uma situação em um dado caso e de atribuir, conseqüentemente, determinadas valorações aos membros de uma comunidade. Em grandes linhas, "falando" sobre seus membros, a comunidade vive um processo de organização muito poderoso, em que fixa o status de um indivíduo ou grupo. O ato de "falar" se torna numa força organizadora, que nomeia, valoriza e, conseqüentemente, estabelece limitações entre o que é possível e o que não é.

Chega-se, assim, a pensar que, ao se falar de violência, faz-se referência à "definição de uma situação". Parece simples tal enunciado, mas resulta imprescindível não esquecê-lo quando uma só palavra pode definir situações muito diferentes. Se a comunidade "ao falar" organiza e exerce níveis diversos de controle, a "definição de uma situação" de violência denota alguns problemas na ordem da própria regulação social, tal qual poderia se supor na linha do pensamento de Thomas. Neste sentido, a "definição de uma situação" de violência por parte de indivíduos ou grupos caracteriza uma situação social na qual os envolvidos se apresentam pouco "integrados" aos mecanismos de regulação impessoais, ao aparecer submersos em relações que, ao serem inevitáveis (por sobrevivência imediata), se tornam pesadas. As experiências coletivas de conflito definem uma situação de violência quando a comunidade já nem sequer parece "falar" mais sobre os que estariam envolvidos nelas. Mas será que o que pareceria estar na motivação dessas "experiências" é simplesmente uma "definição de uma situação" de violência? Não estaria, antes, no estabelecimento de um repertório de antagonismos sociais em torno de experiências contrastadas de uma prévia construção da realidade social?

\section{A violência}

Ao se tratar o fenômeno da violência, a referência aos "círculos sociais" simmelianos parece remeter a uma preocupação com uma ordem de significação importante que lhe tem sido atribuída, fundamentalmente, desde os anos 60. Claro está que a violência fez parte de uma preocupação consolidada em 
vários momentos históricos da vida social, como muito bem o manifesta o estudo já clássico de Georges Sorel (1993), ao associar greve política com a violência nos conflitos próprios do século XIX. Por exemplo, no "Apêndice II: apologia da violência” (1908), da citada obra, Sorel vai manifestar: "Hoje, não hesito em declarar que o socialismo não pode subsistir sem uma apologia da violência" (237). O importante a destacar nestas reflexões é uma definição de violência que não parece dissociada de um aparente sentido político, fazendo parte de um contexto histórico em que "ora se empregam os termos força e violência como referência aos atos da autoridade, ora com referência aos atos de revolta" (ibidem: 146). Tratando-se de uma definição de violência de caráter estritamente "político", o "ator" ou "sujeito da história" aparece redefinido a partir de relações sociais que permitem à luta de classes se erguer como o contexto de uma dinâmica de conflituosidade precisa.

Em todo caso, pode-se considerar que surgiu, durante os anos 60, uma verdadeira diversidade de "representações" sobre a violência, à luz do aparecimento, por exemplo, de particulares mobilizações sociais, políticas e culturais. Assim, compreende-se que a "alta ordem de significação" que a violência passa a obter é derivada da constatação de experiências subjetivas ou coletivas de discriminação e exclusão em uma diversidade de cenários culturais, políticos e institucionais. A violência física, psicológica, política, cultural, verbal, de gênero, ou de tantas outras maneiras passa a ser entendida como o uso deliberado da força muito além do esperado, definindo uma situação social de instabilidade e de relações de poder que, arbitrariamente construídas, tornam-se alvo de questionamentos (Misse, 2006).

Ao devir do latim "violare", o significado mais preciso e difundido do termo violência pareceu sugerir a suposta "violação do pacto" social ou "contrato social". Se bem que esta "violação" possa ser entendida como sinônimo de crime, ${ }^{3}$ existem elementos, como a opressão e o sentimento de injustiça que, para Moore (1987), podem representar uma clara ruptura com esse pacto. A obediência a normas de convivência básicas e a adesão aos valores coletivamente em pauta entram em crise, tornando-se visível já não mais o acordo que legitima "o pacto", mas sim uma ação que realiza uma "definição de uma situação" social e moral de injustiça e opressão: "[...] superar a autoridade moral do sofrimento e da opressão significa

\footnotetext{
3 Ao analisar o que denomina "criminalização da pobreza", Wacquant (2005: 28) afirma que: "é tentador encarar explosões de violência coletiva 'vinda de baixo' como sintomas de crise moral, patologias das classes baixas, ou como tantos outros indícios de iminente ruptura societal da 'lei e da ordem'”.
} 
persuadir a si próprio e aos outros de que é tempo de mudar o contrato social. Mais especificamente, as pessoas passam a acreditar que um novo e diferente conjunto de critérios deve entrar em vigor" (Moore, 1987: 123). Desta maneira, uma violência reativa deixa de ser considerada como uma violação do contrato social, instituindo-se numa "inevitável" expressão de resistência política.

Assim, a violência pode ser análoga a manifestações próprias da agressividade, o controle, a exclusão e o estigma, como também de atitudes reativas que fazem dela um mecanismo de abertura de espaços sociais e de novas possibilidades nas definiçõos de situações sociais e culturais concretas. Como bem se pode perceber, a violência pode ser representada como o "motor da história", como obtendo visibilidade social no seu significado político; mas, também, pode adquirir dimensões existenciais e psíquicas, simbólicas e estéticas, tal qual, por exemplo, aconteceu no caso de algumas vanguardas culturais (Martuccelli, 1999). Parece ingressar no leque de repertórios culturais que irão definir uma construção do sentido social para indivíduos e grupos, ao tornar-se um meio social de ação que denota um estado de conflito aparentemente irreprimível e inexpressável. Não obstante, esta leitura, que supõe que a "definição de uma situação" de violência está ligada ao recurso que um ator emprega para se fazer "presente" ou ser "escutado", parece se limitar a representá-la como uma manifestação apenas travestida da luta de classes, como uma manifestação de caráter estritamente político e vinculada às condições materiais de existência.

Não se pretende transcender esta representação dada à violência. Contrariamente, pretende-se afirmar a sua parcial persistência, embora seja importante considerar evidentes transformações. Talvez seja o diagnóstico desta transformação o desafio mais alentador, no sentido de que resulta importante prever que o contexto da sua cenificação tem-se transformado a tal ponto que parece desfazer-se, cada vez mais, da sua representação e significado "positivo". Ou seja, ausente a legibilidade (e a representação) que a fazia emanar de forma quase direta de relações de dominação evidentes e claras, própria de um "conflito central", percebe-se que a sua atual "crise de representação" deriva numa conseqüente definição ligada a uma prática deslegitimada e "negativa". A crise de uma representação política da violência, dotada de uma significação histórica, trouxe uma definição que a associa ao "fracasso" de eventuais soluções negociadas e pacíficas no contexto que apresentam as democracias atuais. Este tipo de argumentação é, sem dúvida, interessante, quanto mais parece se impor o recurso e o apelo às instituições e à deliberação como uma evidência inconfundível da democracia. Não obstante, este tipo de argumentações também pode resultar muito 
pouco convincente, já que a priori supõem que, através da própria prática da democracia, é capaz de chegar-se a "soluções negociadas". ${ }^{4}$

Afastando-se de certo otimismo político e acadêmico de quem deposita confiança nos recursos objetivos e institucionais na resolução de conflitos, apresenta-se necessário contextualizar a violência num cenário sociocultural e político no qual as experiências coletivas de conflito não parecem alheias à sua expressividade e permanência, ao seu contágio e à sua capacidade de outorgar uma determinada coesão e coerência individual e coletiva. Se for certo que no conflito e confrontação é possível observar o aumento da solidariedade intragrupo (Maffesoli, 2001), pode-se considerar que, numa realidade onde as interações sociais estão pautadas, em grande medida, pela desigualdade e as assimetrias sociais, e pelos interesses práticos de uma ordem institucional que não encontra nada melhor do que tratar de acomodar "novas situações sociais" na antiga normatividade, a violência se ergue numa prática por demais significativa no horizonte político e cultural.

\section{As experiências coletivas de conflito}

Tarrow (1997) afirma que "los movimientos sociales son interacciones mantenidas entre los interlocutores sociales agraviados, de una parte, y sus oponentes y las autoridades públicas, de otro. [...] La acción colectiva - parafraseando Tilly - es el término más activo de dicha interacción y la emplean los actores colectivos en conflicto con sus antagonistas o con las elites" (67-68). Desta maneira, os movimentos sociais se apresentam como desafios de caráter coletivos sustentados por pessoas que compartilham objetivos comuns e solidariedade numa interação mantida com as elites, os oponentes e as autoridades. Sem estar totalmente enganado, Tarrow parece se inclinar por uma compreensão mais cúmplice para os aspectos "estratégicos" dos movimentos sociais: criar, coordenar e manter essa interação é a contribuição específica dos movimentos sociais, mas que só aparecem quando se dão as oportunidades políticas para a intervenção de agentes sociais que normalmente carecem delas (ibidem: 17).

Aparentemente, o "sujeito coletivo" só aparece como produto de plenas condições "estruturais” (política e economicamente falando) e é reconhecível na sua seqüencialidade mantida por interações com seus antagonistas. Neste sentido, o importante parece ser o cenário do conflito, que se apresenta preciso e claro, já que as pessoas se somam aos movimentos sociais

\footnotetext{
${ }_{4}^{4}$ Talvez, de forma análoga, Moore (1987) se referirá ao perigo de certas sociedades que possuem formas de controle de toda rebelião e resistência social, sociedade na qual a injustiça é tolerada e vista como inevitável, asfixiando toda a possível indignação moral gerada por um sentimento de injustiça.
} 
como resposta às oportunidades políticas preexistentes ou desenhadas $a$ priori por movimentos que lhes precederam. Com o conceito de "estrutura das oportunidades políticas" Tarrow se refere a dimensões políticas e sociais consistentes que fomentam ou desestimulam a ação coletiva das pessoas (ibidem: 49).

Até aqui, pode-se, parcialmente, concordar com esta linha de raciocínio, já que dimensões mais centradas no "ator" social ou coletivo (Touraine, 1997; Melucci, 1998) estão visivelmente negligenciadas. Mas o problema mais evidente parece surgir quando esta perspectiva é contrastada com a possível relação que se possa estabelecer entre as situações de conflito emergentes na atualidade com a procaz "estrutura de oportunidades políticas" criadas. Por um lado, é constatável que a interlocução ou interação entre as partes não é moeda corrente e, por outro, que pareceu se estabelecer um cenário de "equilíbrio institucional" marcado pelo uso de um "repertório mobilizatório convencional" que cria situações de aborrecimentos e desilusão com respeito aos resultados de uma concreta manifestação em muitos indivíduos.

A primeira constatação surge de certa suspeita acerca da eventual existência de um cenário ou de uma "estrutura de oportunidades políticas" derivadas de um previsível "conflito central”, medianamente localizável, e surgido de relações sociais antagônicas claras, com um conseqüente projeto político. Dessa forma, o primeiro reflexo de importância que se pode apreciar é a escassa possibilidade de se estabelecer uma ação coletiva duradoura e mantida na "interação". Por outro lado, um segundo reflexo pode recair na mudança no surgimento de mobilizações, criadas de forma espontânea e sem nexos aparentes com a presumidamente consolidada "estrutura das oportunidades políticas”. Estas se caracterizam no confronto direto, numa discursividade que fere a própria imagem dessa preexistente "estrutura de oportunidades", materializando uma "manutenção da ação" mais restrita e sem os incentivos ou benefícios instrumentais que o "marco institucional" possa lhes oferecer.

Mas estas observações não podem ser compreendidas de forma isolada. Sabe-se de diversas maneiras que, na maioria das ocasiões, muitos dos denominados novos movimentos sociais que surgiram nos anos 60 e 70, assim como os que já vinham atuando de forma crescente na cena política e cultural, sofreram uma significativa mutação, ao diagnosticar nos seus campos de luta a viabilidade de uma ação menos radical que proporcionavam as parcerias com o Estado e as mobilizações organizadas nas chamadas ONGs. A respeito disso, estabeleceu-se uma extensa discussão, no sentido de se compreender os novos marcos mobilizatórios, as estratégias e questões 
identitárias que envolviam atores sociais outrora muito críticos, inclusive, a esses tipos de práticas organizativas. Não obstante, a este interessante debate deve-se somar um outro, dificilmente em cena: aquele que percebe que muitos desses "novos atores" organizados, atualmente, têm-se convertido em uma espécie de "nova classe" cuja presença permite o controle do conflito por parte das autoridades políticas e sociais, ao aparecerem subordinados a uma estratégia de ação meramente institucionalizada. As orientações dessa "nova classe" têm deixado o cenário do conflito significativamente vazio, instigando em muitos uma clara sensação de desilusão e apatia. Talvez como correlato da sua própria ação e das suas predileções intelectuais, esta "nova classe" não tardou em desenvolver estratégias de controle e de arranjos sociais que converteram parte do seu próprio repertório de demandas em "política convencional" (Tarrow, 1997). Como bem argumenta Davis (2006: 85), apesar de toda uma retórica sobre democratização, fortalecimento da sociedade civil e capital social, as verdadeiras relações de poder nesse universo das ONGs se apresentam de maneiras muito similares com o clientelismo político tradicional, sugerindo como principal impacto da "revolução" das ONGs e da sociedade civil uma evidente burocratização e desradicalização dos movimentos sociais urbanos.

Este tipo de transformações no cenário político e social se tem desenvolvido de forma muito sutil. Os evidentes ganhos obtidos pela ampliação dos marcos legais e institucionais de participação e representação política, e até os que se evidenciam com a extensa e intensa atividade de diferentes organizações sociais para paliar situações de exclusão e injustiça social, não podem ser ocultados nem esquecidos. Mas há um aspecto analisado de forma muito clara por Berger e Luckmann (2001) que chama para o caráter ambivalente deste "credo da certeza" na institucionalidade, algo a ser considerado posteriormente. O que, sim, se pode antecipar é que as respostas a este devir político podem se entender em algumas das atuais expressões coletivas em que a violência se torna um elemento coadjuvante da sua expressividade.

Estão, conseqüentemente, os movimentos sociais se expressando, de forma crescente, através da violência? Dificilmente se pode responder de forma afirmativa a essa questão. O que deve ser considerado é que deve ser feita uma mudança terminológica a propósito de analisar o nexo entre violência e ações coletivas, e isto se deve a que a vinculação que é possível estabelecer entre violência com práticas coletivas consideradas com um alto

\footnotetext{
5 "As ONGs, observa a ativista e escritora Arundhati Roy, 'acabam funcionando como o apito de uma panela de pressão. Desviam e sublimam a raiva política e garantem que ela não chegará ao ponto de explodir'” (Davis, 2006: 87).
} 
grau de organização e projeção política não é perceptível de forma significativa. Por isso, prefere-se referir a experiências coletivas de conflito ao invés de movimentos sociais, já que o primeiro pode devir num conceito que se define pelo conteúdo contingente e a forma desarticulada e espontânea com a qual parecem se evidenciar as atuais ações coletivas. Assim mesmo, e de maneira fundamental, porque também estas "experiências" manifestam um caráter aparentemente desligado da "estrutura de oportunidades políticas" que se veio consolidando nas últimas décadas.

Até aqui se tem afirmado que o eixo está em pensar a relação existente entre a violência e as experiências coletivas de conflito atuais para assim compreender um pouco mais o cenário de conflituosidade contemporâneo. Tendo em conta as discussões precedentes, consideram-se fundamentais algumas idéias norteadoras em torno à violência. Primeiramente, a crise radical da sua representação atual; em segundo lugar, a sua conotação como própria do sentimento de insegurança existente nas relações sociais; logo, a sua materialização como eventual resposta às assimetrias na falta de laços sociais e filiações de grupo e, por último, que as experiências coletivas de conflito se valem dela para, justamente, poder estabelecer um campo de conflituosidade concreto ou uma "definição de uma situação" social de conflituosidade. Levando em consideração não unicamente o seu caráter político, como pode ser representada a violência hoje? A suposta "imprevisibilidade" da sua expressão denota transformações significativas no entendimento das experiências coletivas de conflito na atualidade?

\section{A violência previsível}

As reiteradas suspeitas acerca de uma representação da violência como própria das diferentes instituições da modernidade chegam ao seu amadurecimento nos anos 60. Aqueles diagnósticos realizados pela Teoria Crítica pareceram se tornar evidentes. A escola, a família, os presídios e o sistema político, de entre outras instituições, entram em cena para ser alvos de uma série de críticas. Assim, a violência aparecerá associada às funções próprias das instituições socializadoras, que disciplinam, controlam e monitoram a vida individual e social (Foucault, 1976; Goffman, 2001). A vida institucional é apresentada como inerente a uma determinada lógica política e socioeconômica e como própria de um poder opressor que pode se localizar tanto no espírito e desenvolvimento do capitalismo (e na sua ordem normativa), como no histórico conservadorismo cultural.

Desta forma, fica evidenciada como a vida institucional tem manifestado uma dinâmica sob o fogo cruzado do disciplinamento, por um lado, e da liberação de supostos laços pré-racionais, por outro. Ainda que sejam 
reconhecidas as histórias de liberação que acompanharam a dinâmica da modernidade, a lógica disciplinar e uniformizadora estabeleceu-se, também, em fator constitutivo dela (Wagner, 1997). Assim, as instituições, pelo simples fato de reger a vida coletiva, controlam a conduta, estabelecendo padrões previamente definidos e canalizando-a numa direção específica. Este caráter controlador (e disciplinador) é inerente à institucionalização enquanto tal. Dessa forma, afirmar que uma concreta atividade individual ou coletiva (política, sexual, etc.) foi institucionalizada representa afirmar que tem sido finalmente submetida ao controle social (Berger e Luckmann, 2001). Sob esta perspectiva, a violência era definida como indissociável da lógica institucional existente e, como era previsível, um cenário de alta conflituosidade social e uma violência reativa não se fizeram esperar, emergindo grupos sociais autodefinidos como excluídos nas diferentes reivindicações dos denominados novos movimentos sociais.

Num cenário de uma nova expansão de relações de poder econômico e político, surgem relações sociais que não tinham sido construídas sob a forma de subordinação (Laclau e Mouffe, 1987). Assim, novos sujeitos políticos começam a se constituir através de relações antagônicas com novas formas de subordinação, prefigurando o que Laclau e Mouffe (ibidem: 204-205) denominaram a "pluralidade do social" e o "pluralismo dos sujeitos”. Se isto representa uma politização ainda mais radical e crescente, a violência pareceu representar-se como enraizada naqueles problemas que fazem parte dos "processos de socialização" e as eventuais "deficiências" de integração social. Se a socialização se define como a "internalização de códigos sociais" concretos, pode-se dizer que a violência foi o produto de situações de conflito e relações de poder que traduzem a emergência de uma forte exteriorização do subjetivo (mundo da vida) em resposta a uma debilitada interiorização do objetivo (sistema). Diferentemente do pessimismo da Teoria Crítica, este novo contexto histórico parece desenhar a possibilidade e a capacidade por sacudir-se da "colonização do mundo da vida pelo sistema" (Habermas, 1988).

A proliferação de espaços políticos e sociais radicalmente novos e diferentes é o que se tem herdado das mudanças políticas, econômicas, sociais e culturais dos anos 60 e 70. Neste contexto, os cenários de disputa política e discursiva parecem também se deslocar de forma incessante, o que leva a tornar-se cada vez mais problemática a definição ou o estabelecimento de

\footnotetext{
${ }^{6}$ No sentido que Dubar (2005: XVII) define: “A socialização se torna um processo de construção, desconstrução e reconstrução de identidades ligadas às diversas esferas de atividade que cada um encontra durante sua vida e das quais deve aprender a tornar-se ator".
} 
"um conflito" concreto, a clara "definição de uma situação" de conflituosidade. Isto se relaciona com o caráter inovador que portavam os novos movimentos sociais, já que "a través de ellos se articula esa rápida difusión de la conflictividad social a relaciones más y más numerosas" (Laclau e Mouffe, 1987: 179). Mas, o fato de se "fragmentar" o cenário da conflituosidade, não deve supor o abandono, na perspectiva de alguns, de uma representação ainda "positiva" da violência, enquadrada no significado histórico das mudanças políticas e sociais. Claro está que, quando a violência emana de uma relação social antagônica clara, surgida da "definição de uma situação" de conflituosidade precisa e estável, a sua presença é previsível e localizável. Não obstante, a "pluralidade do social" não necessariamente tornou difusa a visibilidade da violência, mas, contrariamente, proliferou-a pelos diversos cenários de subordinação e antagonismo, fazendo parte, de forma crescente, de uma multiplicidade de novos cenários e experiências coletivas de conflito.

Alain Touraine (2006a) manifestou que os levantes do mês de novembro de 2005 nas periferias urbanas da França desenham um conflito próprio da "desintegração dos integrados". Segundo Touraine, não é que os jovens manifestantes não estivessem totalmente "integrados" na sociedade francesa, mas o estavam de uma forma traduzível em frustrações pessoais e expectativas insatisfeitas. O trabalho e a escola, agentes socializadores por excelência, pareciam ter-se tornado instituições incapazes de continuar se legitimando como veículos de inclusão e ascensão social. Como conseqüência, as instituições viram obstáculos ou instrumentos de exclusão social metapolíticos, reduzindo-se a confiança que se possa ter nelas. Parece curioso pensar que, para Touraine, as frustrações pessoais e as expectativas insatisfeitas sejam as causas e motores da violência urbana da França no ano de 2005, mas tudo indica que a revisão das possibilidades de legitimação social das instituições políticas e sociais resulta inevitável. Indo mais longe, pode-se afirmar que resulta central a visão da frustração pessoal como interpretação válida para compreender a violência, na medida em que o indivíduo que participou dos protestos, segundo Touraine, atuava sob o que se pode compreender como fins instrumentais e escolhas racionais.

Touraine não estava nem totalmente enganado, nem totalmente certo. Apesar de entrever que os conflitos também preconizavam ausências nos mecanismos políticos integradores e certos mal-estares culturais de muitos jovens migrantes, não atribuiu uma considerável dimensão interpretativa às bases do funcionamento da democracia como causa do fenômeno. Touraine pareceu realizar uma interpretação similar à realizada sobre as desordens urbanas dos anos 80 nos Estados Unidos, na França e na Inglaterra. Estas desordens, segundo Wacquant (2005), combinavam duas lógicas: a de ser 
um protesto contra a injustiça racial com raízes no tratamento discriminatório, e a de ser uma manifestação da população mais empobrecida, que se revolta contra a privação econômica e as desigualdades sociais crescentes; desordens que se valiam da arma única que praticamente possuíam: a ruptura do "pacto social" ou do "contrato social" com o recurso da força. Peralva (2006), diferentemente de Touraine, dirá que os levantamentos de 2005 na França eram "expressivos", e não tanto na ordem da "instrumentalidade", sugerindo a presença de casseurs políticos cuja perspectiva seria protestar contra políticas públicas que pretendiam adormecer os males que afetavam as populações dos bairros populares e retardavam as mudanças efetivas das suas condições de vida. De uma forma ou de outra, a violência era o produto de um "sujeito coletivo" que parecia ter as mesmas reivindicações dos jovens de classe trabalhadora, quer dizer, emprego, ensino de qualidade, moradia, acesso a serviços públicos em geral e tratamento justo por parte das "forças da ordem". O que se reivindicava era uma chamada de atenção pública, acusando as carências na integração social e política de muitos jovens das periferias urbanas. É, por isso, que a visão da frustração pessoal e o diagnóstico de desintegração social se apresentam interligados.

Aqueles que não se sentem plenamente inseridos na discursividade e na materialidade do mundo social "real" são os que, justamente, mais se enfrentarão à insegurança do mundo que habitam. Insegurança representada por causa do jogo da distinção social e da suspeita de que as suas vidas cada vez mais se vêem assumidas por "marcos institucionais" que tornam "a realidade" deficitária. Preferencialmente os mais jovens, e ao contrário do que se poderia supor, parecem definir situações de ter "falsos" empregos, de frequentar "falsas" escolas, de subsistir em uma "falsa" economia ou de participar de uma "falsa" democracia, ou seja, de não poder viver a não ser "falsas" atividades. Mais do que protestos para "usufruir" de direitos civis e sociais conquistados historicamente, o que parece estar em jogo é uma ironia às "estruturas de oportunidades políticas" e à "política convencional", ambas surgidas após os novos movimentos sociais dos anos 60 e 70. A violência, assim, parece se constituir na resposta à ficção e à dominação de um mundo social "desrealizado" (Martuccelli, 1999). Lembra-nos que, fora as "grandes conquistas" sociais e políticas da modernidade, fora a institucionalidade e legalidade construídas para o "bem comum", existe um "outro" mundo que dificilmente se deixa transparecer: aquele que denota o conjunto de elementos que asseguram a dominação social justamente naqueles procedimentos que se criaram para possibilitar o desenvolvimento individual e social.

Por outro lado, a violência não é o simples efeito da "definição de uma situação" na ordem das frustrações e da desintegração social, mas o 
mecanismo pelo qual se percebe que as chances de uma abertura de espaço de expressão social vão aumentando e se intensificando, dinâmica na qual o lugar dos meios de comunicação resulta fundamental (Peralva, 2006). Ao mesmo tempo, e como bem sustenta Wieviorka (2006), a violência também tipifica uma "negação da subjetividade" e uma negação de reconhecimento sociocultural, assim como uma reação à ausência de visibilidade social. Por isso, é no não-reconhecimento mútuo que a violência encontra as suas brechas e que começam a prefigurar-se e fundar-se experiências coletivas de conflito. Assim, a violência dá sentido social e define uma situação específica de desequilíbrios na ordem da indignação, da invisibilidade e da exclusão social. Por meio dela, parece se tornar possível o estabelecimento de um espaço de conflito, podendo-se constatar que, quanto mais performática a violência se expresse, maiores serão as possibilidades de construir espaços de visibilidade e possível interlocução. Lembre-se que, quando os neozapatistas do México surgiram do meio da selva Lacandona, no ano de 1994, e atiraram alguns poucos disparos durante uns 12 dias, o que estava em jogo era a possibilidade de dizer "existimos" e estabelecer uma relação social antagônica clara e previsível, localizável e duradoura (Gadea, 2004). Resulta evidente que a dimensão do reconhecimento sociocultural, no sentido que Honneth (1997) analisa, está presente no mecanismo expressivo que a violência tipifica ao pretender tornar possível o estabelecimento de um espaço de conflituosidade, constatando-se, inclusive, que quanto mais performática a violência se expresse, maiores serão as possibilidades de construir espaços de visibilidade e eventual interlocução. Não obstante, uma espécie de "violação da moralidade coletiva" e do "pacto social" são o argumento para reconhecer em muitos que as regras e os elementos estruturantes desse "pacto" são, de fato, injustos e opressivos. Quer dizer, que além da procura por reconhecimento sociocultural e político, trata-se de associar experiências coletivas de conflito com uma certa capacidade de "indignar-se" perante o que se tem definido como uma ordem injusta e opressora, uma ordem que estaria impossibilitando, em alguns, a esperada adesão aos valores criados pela "comunidade" particular de pertença. ${ }^{7}$

Embora Wieviorka (2006: 211-212) afirme que a violência vem significar o "não-conflito, a ruptura, o fim de uma relação", a violência parece instituir-se em algo significativo: torna visível uma ação estruturada em termos de antagonismos e desenha uma "definição de uma situação" de

\footnotetext{
7 De certa maneira, faz-se referência à "capacidade intelectual" de alguns para reconhecer que as regras são opressoras. Tal reconhecimento pode ser entendido como uma forma de percepção moral em termos dos padrões de comportamento existentes, ainda que em grande parte suprimidos (Moore, 1987: 124).
} 
conflituosidade ali onde antes não existia. Em definitivo, não se pode afirmar que a violência é contrária ao conflito e que a sua presença conspira contra um processo de subjetivação coletiva: ela permite o estabelecimento de experiencias coletivas de conflito, no sentido em que as situa numa relação de subordinação e antagonismo claro.

\section{A violência imprevisível}

Wieviorka (2006: 216-217) está certo quando argumenta que, para se poder pensar a violência, é necessário pensar o lugar do sujeito suprimido, impedido, inencontrável, a perda de sentido ou o seu excesso. Isto possibilitaria constatar uma grande variabilidade da própria violência. Não obstante, não parece se perceber nas suas análises em que sentido a violência adquire a variabilidade sugerida. Em todo caso, parece adquiri-la na sua simples expressividade, já que a violência jamais é estável por muito tempo, controlada por seu protagonista ou fixada por este a um limite ou outro onde teria a sua intensidade regulada.

A variabilidade da violência pode ser entendida no seu ingresso em campos de conflituosidade e de relações sociais de subordinação. A variabilidade não está nos seus devaneios expressivos, mas nas características das relações sociais em que entra em cena. Por isso, a definição de uma realidade social não pode continuar partindo da dicotomia integração/exclusão sem se estabelecer de forma clara a que tipo de realidade se está fazendo referência e a que cenário social se supõe que indivíduos ou grupos sociais deveriam estar integrados. A que se integrar? Se admitirmos que as sociedades nunca foram homogêneas ou, eventualmente, "hiperintegradas", e o que de fato se consolidou foi uma "idéia de integração", observa-se que o que existem são diversos espaços aos quais indivíduos ou coletividades podem se integrar. A própria integração e exclusão social são simples atributos que se outorgam a qualquer indivíduo ou grupo que ocupa um determinado lugar em certas formas de relação social: analisar os fenômenos da integração implica compreender que indivíduos ou grupos sociais podem estar integrados em determinada "forma de relação" e excluídos de outra (Gadea, 2007). Perdida a ilusão de consenso macrossocial, resta fazer referência à tradição pragmática e considerar a idéia de "consensos relacionais contingentes".

Talvez isto seja análogo ao que Touraine (2006b) expressa quando diagnostica o "fim do social" ou a "destruição da sociedade". Nestes termos, Touraine parece sugerir a desintegração social e a ruptura dos vínculos sociais característicos de uma realidade que ainda era "social". A sociedade não estaria mais estruturada em torno de um "conflito central", como foi o caso ao longo de toda a época industrial clássica, em que as condutas 
de violência se traduziriam em uma contestação política que procuraria organizar-se em longo prazo, "assim como lutas e engajamentos, que podem chegar a reivindicações negociadas, pressões políticas e movimentos sociais trazidos por um projeto baseado na subjetividade dos atores" (Wieviorka, 2006: 207). Ou seja, em instâncias em que a realidade estava desenhada sob um "conflito central estruturante", por exemplo, na luta de classes, a violência não era definível na própria expressividade das ações, e sim numa relação de conflito e de contestação política e social (pressões diversas, movimentos de operários, etc.). A violência entrava no terreno do previsível, do possível e até do próprio desvio da relação de conflito. Mas o que acontece quando se tem a incapacidade de localizar esse tal "conflito central"? O que acontece quando a violência não parece emanar de um conflito claramente estabelecido? A contestação política e a relação de conflito parecem se tornar tarefas de construção incessante ou, melhor, de possibilidades que correm paralelas à contingência própria da construção do sujeito coletivo.

A possibilidade de encontrar-se "o conflito", as regras sociais e culturais a serem desafiadas, a crítica social e o estabelecimento de relações sociais antagônicas e sob a base da subordinação é todo um desafio contemporâneo. Trata-se, inclusive, de um desafio que toma conta da possibilidade de construções discursivas e práticas sociais que desenham uma lógica da identidade. Se for o princípio de incerteza, a simulação e a ironia características da nossa atualidade, o conflito e a própria violência não escapam desta crispação do estado da cultura: a invisibilidade das "regras do jogo" e a dificuldade da "definição de uma situação" de conflituosidade. Se o conflito é o resultado do estabelecimento de regras de jogo claras surgidas de relações sociais antagônicas e que denotam subordinação e previsibilidade, a violência se apresenta como sinônimo da imprevisibilidade do conflito, da invisibilidade das regras do jogo e da neurose de um estado da cultura que não consegue fugir da sentença de que todo o conflito estaria motivado pela intenção por restabelecer "uma ordem" social preexistente. Sendo assim, as experiências coletivas de conflito se expressam através da violência não tanto porque, de fato, careçam de um projeto político e cultural concreto, mas porque transitam no ambíguo território da invisibilidade de um "conflito central" e do seu próprio projeto e identidade.

Isto não pretende concordar com argumentos que consideram que uma idéia de uma política do sujeito implica esforços por transformar a violência em conflito (ibidem: 221), quer dizer, encorajar os atores a reconhecer e aceitar interlocutores com quem vale mais trocar e, em definitivo, ingressar no jogo da previsibilidade política. Ao mesmo tempo, não resulta convincente pensar que, ao fazerem uma "definição de uma situação" de 
conflituosidade na experiência da violência, os sujeitos sociais são incapazes de construir um projeto político e cultural e uma identidade. Na tentativa por demarcar relações sociais de exclusão e subordinação, de lesão moral e reconhecimento sociocultural, instauram-se diversos projetos que são elaborados e construídos em função de experiências sociais e de vivências e interações específicas: "o projeto", como bem afirma Velho (1981), é uma tentativa consciente de dar um sentido ou coerência a uma experiência fragmentadora. Se a violência é considerada um mecanismo pelo qual as chances de uma abertura de espaço político e social vão aumentando e se intensificando, pode-se afirmar que ela é parte importante nos projetos políticos e culturais de indivíduos e grupos. Assim, a violência parece se tornar uma espécie de linguagem organizadora, forma de identificação e de projeto de vida que distingue os iguais em situações sociais concretas. Muniz Sodré (2006: 39) menciona, acertadamente, que a "violência é uma espécie de contralinguagem comunitária; é uma espécie de contralinguagem em que aquele que não tem moeda, aquele que não está discursivamente inserido na esfera hegemônica, por educação, por capital social, conhece uma espécie de exceção soberana que incita ao refazimento imaginário de relações sociais”. A violência toma forma como uma linguagem organizadora ou uma "contralinguagem comunitária" no sentido de realizar uma "definição de uma situação" de conflituosidade e, fundamentalmente, ao estar ausente o "conflito central" previsível e localizável, organizar uma determinada "forma de relação" de poder e resistência.

Por isso, para quem o sentimento de indignidade pessoal assume dimensões expressivas na vida cotidiana, a suposta ausência de identidade, ou a sua eventual crise, não é algo verdadeiramente possível de se constatar. Para estes, não há opções quanto à sua identidade, o que é algo que parece confuso para aqueles que, como Wieviorka, vêem nos "excluídos" um ator social em potência, na medida em que possam "se apropriar" das "regras do jogo" político. É na invisibilidade (e não na ausência) de um projeto e identidade onde se desenha o terreno que levaria a uma "definição de uma situação" de conflituosidade através da violência. Se a ordem social ou "a comunidade" não pareceu ter-lhes sugerido ou outorgado um espaço concreto e visível aos que realizam este tipo de definição de situação. É oportuno considerar que a "sua identidade" é algo que os pode alcançar de forma súbita. E esta sim pode devir numa crise real, e não a pseudocrise de que estariam fazendo parte aqueles passíveis de proteção e compreensão, lutadores por um espaço debaixo do sol. A violência é, desta maneira, o resultado da desorientação social e da incapacidade por estabelecer compromissos sólidos com "a comunidade”. 


\section{A violência (in)visível}

Nos dias 8 e 9 de março de 2007, nas cidades de São Paulo e de Montevidéu, manifestantes saíram às ruas para protestar pela presença no Brasil e no Uruguai do presidente dos Estados Unidos, George W. Bush. Em Montevidéu, aproximadamente 100 jovens "encapuzados", ao grito de "Bush fascista", protagonizaram uma violenta manifestação, apedrejando prédios públicos e comerciais (um local de McDonald's e um da Igreja evangélica "Pare de sufrir"). Este acontecimento, assim como o confronto com a polícia e os cânticos contra a visita presidencial e o governo uruguaio, tiveram como saldo a prisão de 15 jovens. ${ }^{8}$ Sabe-se que, aparentemente, estes manifestantes faziam parte de uma variedade de organizações políticas e sociais consideradas "radicais" ("Fogoneros", "Plenaria Memoria y Justicia", "Corriente Clasista y Combativa", de entre outras), mas isto não é suficientemente significativo para poder explicar o acontecido. Aliás, o argumento que explica a violência dessa manifestação a partir da pertença dos envolvidos a grupos políticos e sociais específicos e "minoritários" pouco pode contribuir. Isolando o caráter supostamente organizado da manifestação, pode-se oferecer uma explicação menos limitada.

Como bem menciona Martuccelli (1999: 160), a "violência aparece como sendo negativa e sob a forma de riscos que a sociedade se mostra incapaz de controlar". Ao mesmo tempo que a violência se torna "ilegível" socialmente, como desencaixada do repertório que a fazia parte de jogos políticos e ideológicos estáveis, apresenta-se o panorama de um sentimento de insegurança próprio de uma sociedade exposta a riscos. Riscos que se traduzem em temores, sejam com a contaminação de um rio, como àqueles que nos podem hipotecar a capacidade aberta pelas novas dinâmicas sociopolíticas e culturais de auto-reflexividade e autonomia individual. Assim, sendo de caráter aparentemente subjetivo, a violência vira uma maneira de "ter experiência" do mundo exterior, de ser ou de se sentir exposto a ele (ibidem: 159). Dissolvidos referenciais "classistas" ou de expressões políticas diversas, parece reforçar-se uma representação da violência percebida como perturbadora e "negativa", incômoda e incompreensível, um risco a mais no repertório das incapacidades de controle.

\footnotetext{
8 "Ya sobre la hora 22.30 la Policía realizó las primeras detenciones. Para entonces el grueso de los incidentes había transcurrido. El más grave fue el vallado colocado sobre Colonia y Florida, consumado por unos 15 jóvenes encapuchados y armados con piedras, palos, cócteles molotov y grapas “miguelitos'”. [...] Precisamente, la Jefatura envió a los lugares afectados varios equipos de efectivos. Una Unidad de Guarda Metropolitana practicó entre 10 y 15 detenciones [...]" (Jornal "El País”, 10 de março de 2007, Montevidéu, Uruguai).
} 
Visto isso, a violência está aí para indicar não só mudanças na ordem dos critérios mobilizatórios atuais, mas sim para compreender que as experiências coletivas de conflito realizam uma "definição de uma situação" de violência como uma espécie de contestação e resposta a situações sociais submetidas a "processos de negociação" que ameaçam o indivíduo e os seus "círculos sociais". A "estrutura das oportunidades políticas" a que Tarrow se refere não só estão sendo definidas como um possível e "inalcançável" território no qual se poderia aspirar ingressar, ou como um simples cenário "mobilizatório convencional" pouco atento a novas demandas e mudanças políticas e sociais. Antes parece se definir como um fator ameaçador, à hora de constatar-se que representa para o indivíduo uma satírica normatividade que apela à "internalização" da sua condição de excluído e "desvinculado" por problemas meramente subjetivos ou relacionais. Sem dúvida, isto denota a diversificada precarização que define indivíduos e grupos sociais na atualidade, precarização que parece proporcional ao aumento da desconfiança que muitos, de forma crescente, parecem ter do "mundo objetivo" e "real", dos dispositivos sociais postos em funcionamento para eliminar riscos e inseguranças.

O que pode estar por trás das ações desses jovens de Montevidéu, nos seus protestos contra o "imperialismo" e Bush? Uma politização radicalizada? Um sujeito coletivo que emerge no contexto do neoliberalismo? Talvez se possa responder positivamente a estas questões. Mas, tal qual se mencionou anteriormente, o sentido da violência acusa uma eventual resposta às "assimetrias de poder" na falta de laços sociais e filiações de grupo. Ou seja, que uma "definição de uma situação" de violência designa uma situação de assimetria e desigualdade no estabelecimento ou ausência de vínculos sociais e filiações a grupos. É a incapacidade ou impossibilidade de estabelecer e se inserir em "círculos sociais" a razão para que muitos indivíduos sintam que os seus sofrimentos se relacionam com a praticamente nula "interiorização" das regras do jogo numa realidade cada vez mais exigente em auto-reflexividade e autonomia individual. Assim, as experiências coletivas de conflito só parecem se constituir a partir do ingrediente da violência quando os seus protagonistas se encontram em reduzidíssimos "círculos sociais" de implicação prática no mundo (Simmel, 1977) e sentem que não podem se autoconceber governados a partir do seu interior pela falta de uma "socialização" na "estrutura de oportunidades" que foram criadas.

\footnotetext{
${ }^{9}$ A este respeito, Moore (1987: 139) afirma: "O discurso sobre 'autenticidade', 'encontrar-se a si próprio' [...], dificilmente guarda alguma relação com autonomia moral, pois essa corrente de pensamento não consegue enfrentar séria e corretamente a questão de que as coações são necessárias aos indivíduos em benefício da vida em sociedade, ou à margem dela".
} 
Esta tensão aparece de forma mais visível com o mundo dos jovens. As suas filiações de grupo sobre as quais se apoiar e, fundamentalmente, que estariam possibilitando a capacidade de "singularidade à personalidade" (ibidem) são muito reduzidas aos espaços da família e os amigos, ocasionando que se interprete o mundo como "irreal", longínquo, dominador pela "sua exterioridade" e hipócrita. Como muito bem afirma Martuccelli, a violência, neste caso, surge da

enorme tensão que experimentam entre dois extremos: eles são ao mesmo tempo os principais destinatários do discurso moral do autocontrole e, na prática, são um grupo social particularmente exposto à ausência de diversificação de redes sociais que os comprometa dentro da sociedade. Em suma, a pretensa 'imprevisibilidade' moral ou o 'enervamento' dos jovens freqüentemente não é nada mais do que a manifestação do conflito entre um modelo normativo desconectado dos fatos e a sua fraca filiação social. (1999: 172)

Mas, a imprevisibilidade, inclusive, é um diagnóstico que transcende a própria característica das ações destes jovens, já que é igualmente incorporada como diagnóstico social para a eventual emergência das próprias experiências coletivas de conflito. Assim, quando estas "experiências" apelam para o exercício da violência, não se devem ilusoriamente definir como reflexos da ausência de conflitos ou do seu fatal desvio. Contrariamente, a violência parece ser sinônimo de um choque traduzível na ironia para aqueles dispositivos criados para possibilitar e ampliar o desenvolvimento individual e social e, neles, as "estruturas de oportunidades políticas". O sentimento de indignidade, a degradação simbólica e a estigmatização da identidade são elementos que afetam de forma negativa a possibilidade, em muitos, de fazer parte de uma diversidade de "círculos sociais". Neste sentido, a discriminação sentida que conduz à exclusão passa a ser encarada como alvo do que Moore (1987) denomina "indignação moral”. Daqui que se possa supor que, com a violência, realiza-se uma estratégia, paradoxal, de restituir certa organização à comunidade, ao provocar que ela "fale" sobre os que a materializam (lembrando Thomas). É que, ao "falar", se experimenta esse mundo exterior, e o reconhecimento de pertença a ele torna as experiências coletivas de conflito a brecha para nos recordar que as subordinações e antagonismos sociais são contingentes e, assim, tanto a exclusão como os dispositivos de integração a priori idealizados são meramente arbitrários.

Finalmente, na relação entre a violência e as experiências coletivas de conflito viu-se que, historicamente, os movimentos sociais se estruturavam a partir de uma "definição de uma situação" de conflituosidade política 
localizável e previsível, onde a violência era percebida como parte de um conflito preestabelecido. A violência era, para os movimentos sociais, uma forma de expressividade que não aportava nada em si mesma ao campo do conflito. Não obstante, a aparente ausência de um campo de conflituosidade claro, preciso e previsível, subentendido aos olhos de todos, conduz a estabelecer uma mudança terminológica decisiva: trata-se de substituir a categoria movimento social por aquilo que se chama de experiências coletivas de conflito. Qual seria a principal razão para tal mudança? Fundamentalmente o fato de as atuais configurações coletivas de protesto apresentarem um desafio constante na elaboração e distinção entre uma "relação de conflito" e as suas formas de subordinação. Âs vezes, inclusive, porque elas expressam um conflito (por exemplo, a mobilização anti-Bush) que ao definir-se a partir do estabelecimento da violência parece materializar outros cenários de conflituosidade, e não simplesmente aquele que o constitui discursivamente. Por isso, a violência parece encarnar o desejo por estabelecer uma relação de conflito preciso, assim como se constituir fundadora de uma "experiência" capaz de articular uma série de "pautas" no campo da "indignação moral" e a visibilidade social de indivíduos e grupos, tornando visível o que, aparentemente, permanecia inexistente.

Por isso, a violência constatável nas experiências coletivas de conflito indica uma deslocação interessante: a previsibilidade própria de um "conflito central" localizável, surgido de relações sociais antagônicas claras, e a visibilidade de um projeto político e a sua identidade coletiva correspondente são substituídas pela imprevisibilidade da diversidade. Esta imprevisibilidade é própria da "definição de uma situação" de conflituosidade, assim como do conflito entre "estruturas de oportunidades" desvinculadas dos indivíduos que apresentam uma muito débil filiação a grupos ou vínculos sociais.

\section{Referências bibliográficas}

Berger, Peter; Luckmann, Thomas (2001), A construção social da realidade. Petrópolis: Vozes.

Davis, Mike (2006), Planeta favela, São Paulo: Boitempo.

Dubar, Claude (2005), A socialização. Construção das identidades sociais e profissionais. São Paulo: Martins Fontes.

Evers, Tilman (1984), "Identidade: a face oculta dos novos movimentos sociais", Novos Estudos CEBRAP, 4, 11-23.

Foucault, Michel (1976), Vigilar y castigar. México: Siglo XXI.

Gadea, Carlos A. (2004), Acciones colectivas y modernidad global. El movimiento neozapatista. Toluca: UAEM. 
Gadea, Carlos A. (2007), Paisagens da pós-modernidade. Cultura, Política e Sociabilidade na América Latina. Itajaí-SC: Univali.

Goffman, Erving (2001), Manicômios, prisões e conventos. São Paulo: Perspectiva [1 ${ }^{\mathrm{a}}$ ed.: 1961].

Habermas, Jürgen (1988), Teoría de la acción comunicativa. Madrid: Taurus.

Honneth, Alex (1997), La lucha por el reconocimiento. Barcelona: Crítica.

Laclau, Ernesto; Mouffe, Chantal (1987), Hegemonía y estrategia socialista. Hacia una radicalización de la democracia. Madrid: Siglo XXI.

Maffesoli, Michel (2001), A violência totalitária. Porto Alegre: Sulina.

Martuccelli, Danilo (1999), "Reflexões sobre a violência na condição moderna", Tempo Social, 11, 157-175.

Mead, Georg H. (1982), Espíritu, persona y sociedad. Buenos Aires: Paidós [1ª ed.: 1934].

Melucci, Alberto (1998), "Acción colectiva y transformación personal en la era de la información”, Ciudades, 37, 3-11.

Misse, Michel (2006), “A violência como sujeito difuso", in Jandira Feghali, Candido Mendes e Julita Lemgruber (orgs.), Reflexões sobre violência urbana. Rio de Janeiro: Mauad X.

Moore, Barrington (1987), Injustiça: as bases sociais da obediência e da revolta. São Paulo: Brasiliense.

Peralva, Angelina (2006), "Levantes urbanos na França”, Tempo Social, 18, 81-104.

Riechmann, Jorge; Fernández Buey, Francisco (1994), Redes que dan libertad. Barcelona: Paidós.

Schütz, Alfred (s/d), El problema de la realidad social. Buenos Aires: Amorrortu [1ª ed.: 1962].

Simmel, Georg (1977), Sociologia. Madrid: Revista de Occidente.

Sodré, Muniz (2006), "Violência, mídia e política", in Jandira Feghali, Candido Mendes e Julita Lemgruber (orgs.), Reflexões sobre violência urbana. Rio de Janeiro: Mauad X.

Sorel, Georges (1993), Reflexões sobre a violência. Petrópolis: Vozes [1ª ed.: 1906].

Tarrow, Sidney (1997), El poder en movimiento. Los movimientos sociales, la acción colectiva y la política. Madrid: Alianza.

Thomas, William I. (2005) (tradução de Eva Aladro), "La definición de la situación”, Cuadernos de Información y Comunicación, 10, s/1 [1ª ed.: 1923].

Tilly, Charles (1995), "Los movimientos sociales como agrupaciones historicamente específicas de actuaciones políticas”, Sociológica, 28, 13-36, México.

Touraine, Alain (1989), Palavra e sangue: política e sociedade na América Latina. São Paulo: Trajetória Cultural.

Touraine, Alain (1997), Podremos vivir juntos? Iguales y diferentes. Buenos Aires: FCE.

Touraine, Alain (2006a), "Alain Touraine: hay que pasar de una escuela de la oferta a una escuela de la demanda, orientada hacia el alumno” (entrevista), Cuadernos de Pedagogía, 354, Madrid. 
98 | Carlos A. Gadea

Touraine, Alain (2006b), Un nuevo paradigma para comprender el mundo de boy. Buenos Aires: Paidós.

Velho, Gilberto (1981), Individualismo e cultura. Notas para uma Antropologia da Sociedade Contemporânea. Rio de Janeiro: Zahar.

Wacquant, Loïc (2005), Os condenados da cidade. Rio de Janeiro: Ed. Revan.

Wagner, Peter (1997), Sociología de la modernidad. Barcelona: Herder.

Wieviorka, Michel (2006), Em que mundo viveremos? São Paulo: Perspectiva. 